\title{
Efeito do sistema de plantio e da exposição solar sobre a alocação da biomassa no desenvolvimento inicial do eucalipto
}

\author{
Effect of planting system and solar exposure on biomass allocation \\ in the initial growth of eucalyptus
}

\author{
Helio Tonini ${ }^{\mathrm{I}}$, Marina Moura Morales ${ }^{\mathrm{II}}$, Vanderley Porfirio da Silva ${ }^{\mathrm{III}}$, Jorge Lulu ${ }^{\mathrm{IV}}$, \\ Austeclinio Lopes de Farias Neto ${ }^{\mathrm{V}}$
}

\begin{abstract}
Resumo
Este trabalho foi desenvolvido com o objetivo de comparar a alocação da biomassa arbórea, a conicidade do tronco e a relação altura e diâmetro ao longo do fuste de árvores de eucalipto implantadas em um sistema silvipastoril, em diferente exposição solar, e em monocultivo. Os dados foram coletados em 13 árvores-amostra aos 27 meses de idade, selecionadas em função do intervalo de confiança da média dos diâmetros a altura do peito (DAP) e da posição das árvores na faixa de plantio, com face de exposição sul, norte e central. Concluiu-se que na comparação com o monocultivo, as árvores plantadas em sistema silvipastoril apresentaram menor altura total, maior conicidade e maior biomassa na copa. No sistema silvipastoril, não houve efeito da posição da árvore na faixa de plantio sobre a produção total de biomassa na parte aérea, porém, árvores com face de exposição norte foram mais baixas, cônicas e produziram maior biomassa de galhos e folhas nas partes inferiores da copa.
\end{abstract}

Palavras-chave: Sistemas agroflorestais; Conicidade do tronco; Produtividade

\begin{abstract}
This work was developed in order to compare the arboreal biomass allocation, trunk taper, height and diameter ratio, along the stem of eucalyptus trees planted in silvopastoral system in different sun exposure and monoculture. The data were collected from 13 trees at 27 months, selected according to confidence interval average of breast height diameter (DAP) trees position in planting strip, sun exposure (face south, north and central). It was found that compared to the monoculture, the trees planted in silvopastoral system had lower overall height, larger taper and higher biomass in pantry. There was no sun exposure effect for planting strip and total biomass for silvipastoral systems, however, trees with north sun exposure were lower, more conical, produced more branches and leaves in the lower parts of the treetops.
\end{abstract}

Keywords: Agroforestry; Taper; Productivity

\footnotetext{
I Engenheiro Florestal, Dr., Pesquisador da Embrapa Pecuária Sul, Rod. BR-153, Km 632,9, Vila Industrial, Zona Rural, Caixa Postal 242, CEP 96401-970, Bagé (RS), Brasil. helio.tonini@ embrapa.br (ORCID: 0000-0003-1123-7604).

II Química, Dra., Pesquisadora da Embrapa Florestas, Estrada da Ribeira, Km 111, Bairro Guaraituba, Caixa Postal 319, CEP 83411-000, Colombo (PR), Brasil. marina.morales@embrapa.br br (ORCID: 0000-0001-9125-7239)

III Agrônomo, Dr., Pesquisador da Embrapa Florestas, Estrada da Ribeira, Km 111, Bairro Guaraituba, Caixa Postal, 319, CEP 83411-000, Colombo (PR), Brasil. vanderley.porfirio@embrapa.br (ORCID: 0000-0003-4467-5360)

IV Engenheiro Agrícola, Dr., Pesquisador da Embrapa Agrossilvipastoril, Rod. dos Pioneiros MT 222, Km 2,5, Zona Rural, Caixa Postal 343, CEP 78550-970, Sinop (MT). jorge.lulu @embrapa.br (ORCID: 0000-0001-7040-771X)

v Agrônomo. Dr., Pesquisador da Embrapa Agrossilvipastoril, Rod. dos Pioneiros M 222, Km 2,5, Zona Rural, Caixa Postal 343, CEP 78550970.Sinop (MT). austeclinio.farias@embrapa.br (ORCID: 0000-0002-5870-5252)
} 


\section{Introdução}

Nos sistemas silvipastoris, em geral, são adotados arranjos do componente arbóreo no sentido leste - oeste, para permitir maior penetração de luz entre as linhas de árvores, beneficiando as forrageiras no consórcio (INTEGRAÇÃO..., 2013). Com a utilização de espécies florestais e forrageiras adequadas, a arborização de pastagens, pode aumentar a produção e a qualidade das forrageiras e melhorar o desempenho dos animais em ganho de peso, lactação, sanidade e reprodução além de gerar renda pela produção dos multiprodutos florestais como lenha, postes, mourões, lascas, toras, entre outros benefícios socioambientais (MACEDO et al. 2018).

Neste tipo de sistema agroflorestal, o Eucalyptus é um dos gêneros mais utilizados como componente florestal. A sua adoção ocorre devido ao grande número de genótipos/fenótipos disponíveis; a adaptação às condições climáticas brasileiras; a multiplicidade de usos em produtos madeireiros e não madeireiros; o rápido crescimento; elevada produtividade e o domínio tecnológico, já que é a espécie florestal mais estudada no Brasil (MACEDO et al. 2018; CEZANA et al., 2012).

A radiação solar tem um importante papel na distribuição, composição e produtividade florestal sendo o espectro fotossinteticamente ativo, responsável pela excitação das moléculas de clorofila, fornecendo energia para o processo fotossintético (KOSLOWSKI; KRAMER; PALLARDY, 1991). O sistema de plantio pode modificar o regime de radiação promovendo o aumento ou a diminuição da energia disponível para a biossíntese alterando o balanço de energia (PEZZOPANE, 2001)

A Luz é o fator ambiental que gera a maior magnitude de efeitos morfológicos e fisiológicos nas árvores (KOSLOWSKI; KRAMER; PALLARDY, 1991) e a exposição solar é um dos fatores que afetam a produtividade florestal, já que implica em maior ou menor incidência solar nas plantas ao longo do ano. No hemisfério sul, áreas com face de exposição solar sul recebem menos radiação solar durante o ano quando comparadas à face norte (GONÇALVES, 2015).

O ângulo zenital do sol, formado pela linha vertical imaginária que passa pelo topo de uma árvore e os raios solares, varia em função da latitude, da hora do dia e da declinação solar, que por sua vez, varia em função da época do ano. Assim, com os movimentos da Terra, verifica-se que os raios solares atingem a superfície terrestre com diferentes ângulos zenitais, em diferentes horas e épocas do ano, ou seja, em diferentes intensidades durante o ciclo de um plantio florestal (PEREIRA; ANGELOCCI; SENTELHAS, 2002).

Terrenos com menor declividade e/ou exposição norte recebem mais energia solar ao longo do ano e, comprovadamente, tem influência sobre a capacidade produtiva de sítios cultivados com eucalipto (BRAGA et al., 1999; GONÇALVES, 2015).

Na latitude em que se encontra o município de Sinop em Mato Grosso $\left(-11,86^{\circ}\right)$, devido à posição aparente do sol, os raios solares incidem oito meses do ano diretamente nas árvores com face de exposição norte (aproximadamente de 20/02 a 20/10) e em apenas quatro meses nas árvores com face de exposição sul (aproximadamente de 20/10 a 20/02). Estas variações, podem ter influência sobre a alocação da biomassa, sobretudo, em árvores plantadas em faixas e em baixa densidade por hectare, como é o caso de sistemas silvipastoris.

O fato de que na fase juvenil grande parte dos assimilados são utilizados para a formação da copa (SCHUMACHER; CALDEIRA, 2001), permite supor que pequenas variações no ambiente podem provocar modificações fenotípicas significativas nas árvores (PATIÑO-VALERA; KAGEYAMA, 1988), pincipalmente, na partição da biomassa na copa que mesmo para o gênero Eucalyptus ainda não é bem conhecida (RIGHI et al., 2016).

Para Eucalyptus é alta a correlação entre o aumento da área útil disponível ( $\left.\mathrm{m}^{2} / a ́ r v o r e\right)$ e o aumento das dimensões individuais e da biomassa aérea e radicular (BERNARDO et al., 1998; LELES et al., 2001; OLIVEIRA NETO et al., 2003; SANTANA et al., 2008; OLIVEIRA et al., 2009; REINER; SILVEIRA; SZABO, 2011; FERREIRA et al., 2014), indicando que além da alocação da biomassa, algumas características diretamente relacionadas à densidade de plantio como a conicidade do tronco e a relação altura e diâmetro (h/d) podem variar em função da exposição solar em árvores plantadas em faixas e em baixa densidade inicial na comparação com monocultivos.

Neste contexto, este trabalho foi desenvolvido com o objetivo de comparar a alocação da biomassa 
arbórea, a conicidade do tronco e a relação altura e diâmetro ao longo do fuste de árvores de eucalipto implantadas em um sistema silvipastoril, em diferente exposição solar, e em monocultivo.

\section{Material e métodos}

\section{Características do local e do experimento}

A região do estudo caracteriza-se por ser ecótono Amazônia-Cerrado, com clima do tipo Tropical de Savana Aw, segundo Köppen, com temperaturas médias superiores a $18^{\circ} \mathrm{C}$ em todos os meses e estação seca de 4 a 5 meses no outono/inverno (SOUZA et al., 2013).

Para o estudo, utilizou-se uma área de 3 ha, sendo um hectare $(100 \mathrm{~m} \times 100 \mathrm{~m})$, para o monocultivo (F) e dois hectares (200 m x $100 \mathrm{~m}$ ) para um sistema silvipastoril (SP), que fazem parte de um experimento de longa duração denominado de ILPF-corte implantado no campo experimental da

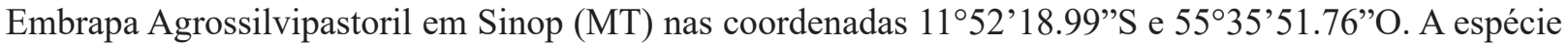
florestal utilizada foi o clone de híbrido Eucalyptus grandis $x$ Eucalyptus urophylla (clone H13) plantado em espaçamento 3,5 m x $3 \mathrm{~m}$ no monocultivo e em faixas de linhas triplas, no sentido leste - oeste, com espaçamento de $3,5 \mathrm{~m} \times 3 \mathrm{~m} \times 30 \mathrm{~m}$ no sistema silvipastoril.

No preparo do solo para o plantio do eucalipto foi realizada uma subsolagem a $60 \mathrm{~cm}$, o sulcamento e a adubação de $350 \mathrm{~kg} \mathrm{ha}^{-1}$ de superfosfato simples. Foram realizadas três adubações de cobertura, um e dois meses após o plantio das árvores com NK, 20-20 (100 gramas por planta) e um ano após o plantio com $400 \mathrm{~kg} \mathrm{ha}^{-1} \mathrm{de}$ NPK 20-05-20. O plantio da braquiária brizanta - cultivar Marandu - foi realizado logo após o plantio das árvores a uma distância de $1 \mathrm{~m}$ das faixas de árvores. Como preparo do solo utilizou-se a gradagem e a adubação de $400 \mathrm{~kg} \mathrm{ha}^{-1}$ com NPK (04-30-16).

\section{Coleta dos dados}

Os dados foram coletados em janeiro de 2014, estando as árvores com 27 meses de idade. A seleção e o abate das árvores-amostra para o estudo da biomassa foi feita selecionando árvores de DAP médio, muito usual em estudos de biomassa com eucalipto como Leles et al. (2001), Oliveira Neto et al. (2003), Oliveira et al. (2008), Santana et al. (2008) e Santos et al. (2012).

Para a seleção das árvores-amostra, utilizou-se o intervalo de confiança da média dos diâmetros a altura do peito (DAP), obtidos com base no inventário florestal contínuo da área, realizado anualmente em parcelas permanentes de 81 plantas $\left(850,5 \mathrm{~m}^{2}\right)$ distribuídas sistematicamente em todo o experimento.

No sistema silvipastoril foram abatidas nove árvores, sendo três na linha central e três em cada uma nas linhas de borda, com face de exposição sul e norte. No monocultivo foram abatidas mais quatro árvores e todas submetidas à compartimentalização da biomassa a cada metro ao longo de todo fuste.

Foram tomadas as massas verde e seca de todos os componentes da biomassa das árvores (galhos finos mortos, galhos finos vivos, galhos grossos mortos $(\geq 2,5 \mathrm{~cm})$, galhos grossos vivos, folhas e tronco com casca). Para a obtenção do peso seco no sistema silvipastoril, foi tomada uma amostra composta das três árvores da linha central, três da linha sul, três da linha norte. No monocultivo foi tomada uma amostra composta (representativa das quatro árvores amostradas) de cada componente da biomassa em cada metro da copa, que foram levadas à estufa a $60^{\circ} \mathrm{C}$, para secar até o peso constante.

O peso seco total foi calculado por:

$$
P S T=(P U T x P S A) / P U A
$$

Em que: PST = peso seco total $(\mathrm{Mg})$; PUT = Peso úmido total $(\mathrm{Mg}) ; \mathrm{PSA}=$ Peso seco da amostra $(\mathrm{Mg})$; PUA $=$ peso úmido da amostra $(\mathrm{Mg})$. 
Para a determinação da densidade básica foram retirados discos com aproximadamente $2,5 \mathrm{~cm}$ de espessura da base do tronco e a $25 \%, 50 \%, 70 \%$ e $90 \%$ da altura total. A biomassa do tronco foi determinada por:

$$
\text { Biomassa do tronco }(\mathrm{kg})=\sum V_{i} x d_{i}
$$

Em que: $V_{i}=$ volume do tronco na seção $i\left(m^{3}\right) ; d_{i}=$ densidade da madeira na seção i $\left(\mathrm{kg} \mathrm{m}^{-3}\right)$.

A densidade básica média por árvore foi determinada conforme a Norma ABCP M 14/70. Também foram comparados a relação $(\mathrm{h} / \mathrm{d})$, ou seja a relação entre a altura total $(\mathrm{m})$ e diâmetro a altura do peito $(\mathrm{cm})$ e a conicidade do tronco obtida por:

$$
C=\sum\left(\frac{d_{i}-d_{i+1}}{L}\right)
$$

Em que: $\mathrm{d}_{\mathrm{i}}=$ diâmetro na seção i $(\mathrm{cm}) ; \mathrm{d}_{\mathrm{i}+1}=$ diâmetro na seção posterior $(\mathrm{cm}) ; \mathrm{L}=$ comprimento da seção $(\mathrm{m})$.

\section{Análise estatística}

Os dados foram submetidos aos testes de Normalidade (Kolmogorov-Smirnov) e homogeneidade de variância (Levene). Para as variáveis que seguiram a distribuição normal e apresentaram variâncias homogêneas entre os tratamentos compararam-se as médias entre grupos (sistema de plantio) pelo Teste T. Para verificar o efeito da posição da árvore na faixa de plantio no sistema silvipastoril, utilizou-se a ANOVA, para o delineamento inteiramente casualizado, em que cada linha de plantio representou um tratamento (linhas com exposição sul $\left(\mathrm{SP}_{\text {sul }}\right)$, central $\left(\mathrm{SP}_{\text {central }}\right)$ e norte $\left(\mathrm{SP}_{\text {norte }}\right)$ ), comparado com a testemunha que foi o monocultivo (F). Cada árvore amostra foi considerada uma repetição e no caso de se detectar diferença significativa entre os tratamentos aplicou-se o Teste de Tukey a $5 \%$ de probabilidade de confiança.

\section{Resultados e discussão}

A média para o conteúdo total de biomassa foi de $54,5 \%$. As médias de umidade por compartimento arbóreo foram: $58,2 \%$ para o tronco e casca, $49,8 \%$ para folhas, $47 \%$ para galhos vivos finos, $52,3 \%$ para galhos vivos grossos e 18,8\% para galhos finos mortos. Não foram observados galhos mortos grossos. O teor de umidade médio das árvores observado neste estudo foi próximo ao observado por Alves (2007) para 15 clones de eucalipto aos 4 anos e em espaçamento de $3 \mathrm{~m} \times 2 \mathrm{~m}$.

Tabela 1 - Análise de variância (quadrados médios) para as variáveis dendrométricas e de biomassa em árvores de Eucalyptus grandis $x$ Eucalyptus urophylla em sistema silvipastoril e em monocultivo aos 27 meses de idade.

Table 1- Variance analysis for the dendrometric and biomass variables of Eucalyptus grandis $x$

\begin{tabular}{|c|c|c|c|c|c|c|c|c|c|c|c|c|}
\hline \multirow{2}{*}{ FV } & \multirow{2}{*}{ GL } & \multicolumn{11}{|c|}{ Variável resposta } \\
\hline & & Dap & $\mathbf{H}$ & Hc & $\mathbf{h} / \mathbf{d}$ & $\mathbf{C}$ & B & BT & BC & BF & BGV & BGM \\
\hline Tratamento & 3 & $0,85^{*}$ & $3,06^{*}$ & 1,48 & $0,064^{*}$ & $0,13^{*}$ & $17,02 *$ & 1,69 & $16,35^{*}$ & $4,56^{*}$ & $11,79^{*}$ & 2,01 \\
\hline Erro & 9 & 0,14 & 0,35 & 0,62 & 0,004 & 0,03 & 10,37 & 4,54 & 3,89 & 0,921 & 1,49 & 0,53 \\
\hline Total & 12 & & & & & & & & & & & \\
\hline
\end{tabular}
Eucalyptus urophylla trees in silvopastoral system and in monoculture at 27 months of age.

Em que: *Significativo a 5\% de probabilidade de confiança; $\mathrm{GL}=$ graus de liberdade; DAP = diâmetro a altura do peito; $\mathrm{H}=$ altura total; Hc = altura comercial; $\mathrm{h} / \mathrm{d}=$ relação altura diâmetro; $\mathrm{C}=$ conicidade do tronco; $\mathrm{B}=$ biomassa total acima do solo; $\mathrm{BT}=$ biomassa do tronco e casca; $\mathrm{BC}$ = biomassa da copa; $\mathrm{BF}=$ biomassa de folhas; $\mathrm{BGV}=$ biomassa de galhos vivos; $\mathrm{BGM}=$ biomassa de galhos mortos. 
A densidade básica média da madeira não variou com o sistema de plantio sendo de $0,444 \mathrm{~g} \mathrm{~cm}^{-3}$ para árvores no sistema silvipastoril e $0,443 \mathrm{~g} \mathrm{~cm}^{-3}$ para o monocultivo, estando dentro do limite inferior $\left(0,419\right.$ a $\left.0,54 \mathrm{~g} \mathrm{~cm}^{-3}\right)$ observados por autores como Carvalho e Nahuz (2001), Alzate, Tomazelo Filho e Piedade (2005), Santos e Sansígolo (2007), Neves et al. (2013) e Protasio et al. (2014) para clones de híbridos de Eucalyptus grandis x Eucalyptus urophylla com idades variando entre 36 e 84 meses.

$\mathrm{Na}$ ANOVA, não foram observadas diferenças significativas entre os tratamentos para a altura comercial, biomassa do tronco incluindo a casca e a biomassa de galhos mortos (Tabela1).

As árvores plantadas em sistema silvipastoril apresentaram menor altura total e relação $\mathrm{h} / \mathrm{d}$ e maior DAP, conicidade e biomassa na copa. A maior produção de biomassa nas copas deveu-se a maior produção de folhas e galhos vivos (Tabela 2). Em $\mathrm{SP}_{\text {norte }}$, a biomassa total produzida superou a de árvores plantadas em monocultivo, e esta diferença, ocorreu devido à maior produção de biomassa na copa. As árvores com face de exposição norte apresentaram-se mais baixas e cônicas quando comparadas às de face sul.

A maior relação h/d $(1,22)$ das árvores no monocultivo (Tabela 2$)$ indicou que já estão sob efeito da competição, uma vez que, proporcionalmente, estão crescendo mais em altura do que em diâmetro. No silvipastoril ainda está ocorrendo o processo inverso, pois esta relação foi inferior a $1(0,97)$.

A maior competição por luz pode ter estimulado o crescimento em altura das árvores no monocultivo e no $\mathrm{SP}_{\text {sul }}$, que recebe menos radiação solar durante a maior parte do ano.

Além da competição por luz, a menor altura e a maior conicidade das árvores em SP, provavelmente, ocorrereu devido às maiores tensões no fuste ocasionadas pela ação do vento que segundo (SCHNEIDER; SCHNEIDER, 2008) faz com que em áreas mais abertas, as árvores direcionem o crescimento para as raízes e as partes inferiores do fuste buscando maior estabilidade.

Tabela 2 - Valores médios e suas comparações para os tratamentos e variáveis analisadas para árvores de Eucalyptus grandis $x$ Eucalyptus urophylla em sistema silvipastoril e monocultivo aos 27 meses de idade.

Table 2 - Mean values and their comparisons to the treatments and variables for Eucalyptus grandis clone $x$ Eucalyptus urophylla trees in silvopastoral system and monoculture at 27 months.

\begin{tabular}{|c|c|c|c|c|c|c|c|c|c|c|c|}
\hline \multirow[b]{2}{*}{ Tratamentos } & \multicolumn{11}{|c|}{ Variável } \\
\hline & $\begin{array}{l}\text { DAP } \\
(\mathbf{c m})\end{array}$ & $\begin{array}{c}\mathbf{H} \\
(\mathbf{m})\end{array}$ & $\begin{array}{l}\text { Hc } \\
\text { (m) }\end{array}$ & $\mathbf{h} / \mathbf{d}$ & C & BT (kg) & $\begin{array}{l}\mathrm{BC} \\
(\mathrm{kg})\end{array}$ & $\begin{array}{c}\text { B } \\
(\mathrm{kg})\end{array}$ & BF & BGV & BGM \\
\hline SP & $10,5^{*}$ & $10,3^{*}$ & 7,5 & $0,97^{*}$ & $1,39^{*}$ & 15,52 & $17,64^{*}$ & $33,17^{*}$ & $6,99^{*}$ & $9,52^{*}$ & 1,13 \\
\hline $\mathrm{F}$ & $9,6^{\mathrm{B}^{*}}$ & $11,7^{\mathrm{A}^{*}}$ & 8,2 & $1,22^{* \mathrm{~A}}$ & $1,07^{\mathrm{C}^{*}}$ & 15,13 & $14,31^{\mathrm{B}^{*}}$ & $29,43^{\mathrm{B}^{*}}$ & $5,18^{* \mathrm{~B}}$ & $6,56^{* \mathrm{~B}}$ & 2,55 \\
\hline $\mathrm{SP}_{\text {sul }}$ & $10,7^{\mathrm{A}}$ & $11,0^{\mathrm{A}}$ & 7,9 & $1,03^{\mathrm{B}}$ & $1,33^{\mathrm{B}}$ & 16,47 & $17,18^{\mathrm{AB}}$ & $33,65^{\mathrm{AB}}$ & $7,44^{\mathrm{AB}}$ & $8,68^{\mathrm{AB}}$ & 1,05 \\
\hline $\mathrm{SP}_{\text {central }}$ & $10,4^{\mathrm{AB}}$ & $10,5^{\mathrm{AB}}$ & 7,9 & $1,00^{\mathrm{B}}$ & $1,31^{\mathrm{B}}$ & 15,37 & $16,18^{\mathrm{AB}}$ & $31,55^{\mathrm{AB}}$ & $5,96^{\mathrm{AB}}$ & $8,80^{\mathrm{AB}}$ & 1,42 \\
\hline $\mathrm{SP}_{\text {norte }}$ & $10,5^{\mathrm{A}}$ & $9,5^{\text {в }}$ & 6,7 & $0,90^{\mathrm{B}}$ & $1,54^{\mathrm{A}}$ & 14,73 & $19,57^{\mathrm{A}}$ & $34,31^{\mathrm{A}}$ & $7,56^{\mathrm{A}}$ & $11,08^{\mathrm{A}}$ & 0,92 \\
\hline
\end{tabular}

Em que:* Significativo a 5\% pelo Teste T; DAP = diâmetro a altura do peito; $\mathrm{H}=$ altura total; $\mathrm{Hc}=$ altura comercial; relação altura total (m) e DAP $(\mathrm{cm}) ; \mathrm{C}=$ conicidade; $\mathrm{BT}=$ biomassa do tronco e da casca; $\mathrm{BC}=$ biomassa da copa; $\mathrm{B}=$ biomassa total acima do solo. $\mathrm{BF}=$ biomassa de folhas; $\mathrm{BGV}=$ biomassa de galhos vivos; $\mathrm{BGM}=$ biomassa de galhos mortos. Médias com mesma letra não diferiram significativamente pelo Teste de Tukey a 5\% de probabilidade de confiança.

A produção de biomassa total individual foi superior no SP com média de $33,17 \mathrm{~kg}^{2}$ árvore $^{-1}$, ou $3,74 \mathrm{~kg}$ a mais produzido por árvore na comparação com $\mathrm{F}$, no entanto, o percentual de biomassa produzida na copa foi muito próximo $(53,2 \%$ no SP e $52,7 \%$ em F), e variou pouco com a posição da árvore na faixa de plantio 51,04\%, 51,29\% e 57,04\% para $\mathrm{SP}_{\text {sul }} ; \mathrm{SP}_{\text {central }}$, e $\mathrm{SP}_{\text {norte }}$, respectivamente.

No silvipastoril, a alocação proporcional da biomassa foi de $48,2 \%$ para tronco e casca, $29,4 \%$ para galhos e $22,3 \%$ para folhas. No monocultivo, este percentual foi de $51,3 \%, 30,9 \%$ e $17,6 \%$, respectivamente, 
corroborando com Righi et al. (2016) ao observarem que apesar das árvores de Eucalyptus camaldulensis responderem ao aumento da radiação solar disponível com o aumento na biomassa total, área de folhagem e o volume da copa, a partição da biomassa mantém proporção constante, ou seja, a espécie mantém uma arquitetura de copa rígida e inelástica.

As árvores em SP produziram mais biomassa nas posições inferiores da copa (Figura 1A e Tabela 3), que pode ser atribuído a maior incidência de luz nos galhos localizados nas partes mais baixas da copa. Neste sistema de plantio, as árvores mantiveram o crescimento de galhos basais em detrimento do crescimento no tronco, particularmente do crescimento em altura.

\section{Tabela 3 - Distribuição da biomassa total da copa em segmentos de 1 metro na copa de Eucalyptus grandis $x$ Eucalyptus urophylla cultivado em monocultivo e em sistema silvipastoril aos 27 meses.}

Table 3 - Total biomass Distribution of canopy in one meter segments in the crown of Eucalyptus grandis clone $\mathrm{x}$ Eucalyptus urophylla grown in monoculture and in silvopastoral system at 27 months of age.

\begin{tabular}{|c|c|c|c|c|c|c|c|c|c|c|c|c|}
\hline \multirow{2}{*}{$\begin{array}{c}\text { Posição na } \\
\text { copa }\end{array}$} & \multicolumn{4}{|c|}{ Folhas (kg) } & \multicolumn{4}{|c|}{ Galhos vivos (kg) } & \multicolumn{4}{|c|}{ Galhos mortos (kg) } \\
\hline & $\mathbf{F}$ & $\mathbf{S P}_{\text {sul }}$ & $\mathbf{S P}_{\text {central }}$ & $\mathbf{S P}_{\text {norte }}$ & $\mathbf{F}$ & $\mathbf{S P}_{\text {sul }}$ & $\mathbf{S P}_{\text {central }}$ & $\mathbf{S P}_{\text {norte }}$ & $\mathbf{F}$ & $\mathbf{S P}_{\text {sul }}$ & $\mathbf{S P}_{\text {central }}$ & $\mathbf{S P}_{\text {nort }}$ \\
\hline 1 & $0^{\mathrm{b}}$ & $0^{\mathrm{b}}$ & $0^{\mathrm{b}}$ & $0,253^{\mathrm{a}}$ & $0,000^{b}$ & $0,000^{\mathrm{b}}$ & $0,000^{\mathrm{b}}$ & $0,727^{\mathrm{a}}$ & 0,331 & 0,339 & 0,289 & 0,37 \\
\hline 2 & 0,043 & 0,141 & 0,064 & 0,225 & 0,394 & 0,403 & 0,258 & 0,351 & 0,956 & 0,423 & 0,581 & 0,365 \\
\hline 3 & $0,328^{\mathrm{b}}$ & $1,025^{\mathrm{b}}$ & $0,508^{\mathrm{b}}$ & $2,507^{\mathrm{a}}$ & $0,950^{b}$ & $1,780^{\mathrm{b}}$ & $1,184^{\mathrm{b}}$ & $4,843^{\mathrm{a}}$ & 0,857 & 0,235 & 0,494 & 0,179 \\
\hline 4 & 0,445 & 2,184 & 1,806 & 1,054 & 0,881 & 2,858 & 3,328 & 1,602 & 0,402 & 0,056 & 0,054 & 0,005 \\
\hline 5 & 1,116 & 0,778 & 1,085 & 1,116 & 1,438 & 0,757 & 1,464 & 1,326 & 0,009 & 0 & 0 & 0 \\
\hline 6 & 0,699 & 0,915 & 0,514 & 0,796 & 0,487 & 0,769 & 0,433 & 0,744 & 0 & 0 & 0 & 0 \\
\hline 7 & 0,756 & 0,964 & 0,845 & 0,742 & 0,434 & 0,816 & 0,828 & 0,696 & 0 & 0 & 0 & 0 \\
\hline 8 & 0,689 & 0,701 & 0,676 & 0,608 & 0,553 & 0,644 & 0,698 & 0,695 & 0 & 0 & 0 & 0 \\
\hline 9 & 0,623 & 0,345 & 0,377 & 0,096 & 0,501 & 0,305 & 0,462 & 0,094 & 0 & 0 & 0 & 0 \\
\hline 10 & 0,422 & 0,32 & 0,088 & ----- & 0,339 & 0,3 & 0,141 & ---- & 0 & 0 & 0 & 0 \\
\hline 11 & 0,047 & 0,063 & 0,003 & ----- & 0,253 & 0,05 & 0,003 & ---- & 0 & 0 & 0 & ---- \\
\hline 12 & 0,017 & ----- & ------ & ----- & 0,061 & ----- & ----- & ----- & ---- & ----- & ----- & ---- \\
\hline
\end{tabular}

Em que:F = árvores em monocultivo; $\mathrm{SP}_{\text {sul }}=$ árvores em silvipastoril com exposição solar sul; $\mathrm{SP}_{\text {central }}=$ árvores em silvipastoril na linha central; $\mathrm{SP}_{\text {norte }}=$ árvores em silvipastoril com exposição solar norte.

Em SP, as árvores produziram maior biomassa de folhas nas posições 1 e $3 \mathrm{~m}$ (Figura 1B e Tabela 3) e até os cinco metros de altura, o acumulado médio foi de $2,15 \mathrm{~kg}(66,05 \%$ do total) contra $1,11 \mathrm{~kg}$ ( $37,3 \%$ do total) no mesmo segmento da copa em F. No monocultivo, as árvores alocaram mais biomassa de folhas a partir dos quatro metros de altura.

A zona em que os galhos morrem depende da quantidade de luz incidente e quanto mais fechado for o dossel mais alta será esta zona (SCHNEIDER; SCHNEIDER, 2008). O fechamento do dossel em F fez com que as árvores alocassem $84 \%$ da biomassa de folhas acima dos 4 metros e, nesta posição, já apresentassem grande biomassa de galhos mortos.

Como a distribuição da biomassa na copa pode variar entre espécies e dentro de uma mesma espécie em função do ambiente e dos tratamentos silviculturais, West (2006) recomendou que se fizessem estudos sobre a distribuição das folhas no dossel antes de se recomendar a altura de desramas. Para os dois sistemas estudados, desramar até uma altura de $4 \mathrm{~m}$ aos 27 meses, representaria uma remoção de 33\% a 
$40 \%$ do comprimento da copa, o que implicaria na remoção de percentuais de folhas entre $39,8 \%$ a $53,4 \%$ em SP, dependendo da face de exposição solar, e apenas 15,7\% em F.

Estas variações têm grande importância prática e devem ser consideradas na aplicação deste tratamento silvicultural e na instalação de experimentos, uma vez que uma mesma altura de desrama não significa uma mesma intensidade de remoção de biomassa da copa (TONINI et al., 2016).

Figura 1 - Distribuição da biomassa total da copa (A), das folhas (B), galhos vivos (C) e galhos

mortos (D) em segmentos de 1 metro na copa de Eucalyptus grandis $x$ Eucalyptus urophylla cultivados em monocultivo e em sistema silvipastoril aos 27 meses.

Figure 1 - Total biomass in the crown (A), leaves (B), live branches (C) and dead branches (D) in one meter segments of Eucalyptus grandis clone x Eucalyptus urophylla grown in monoculture and in silvopastoral system to 27 months.

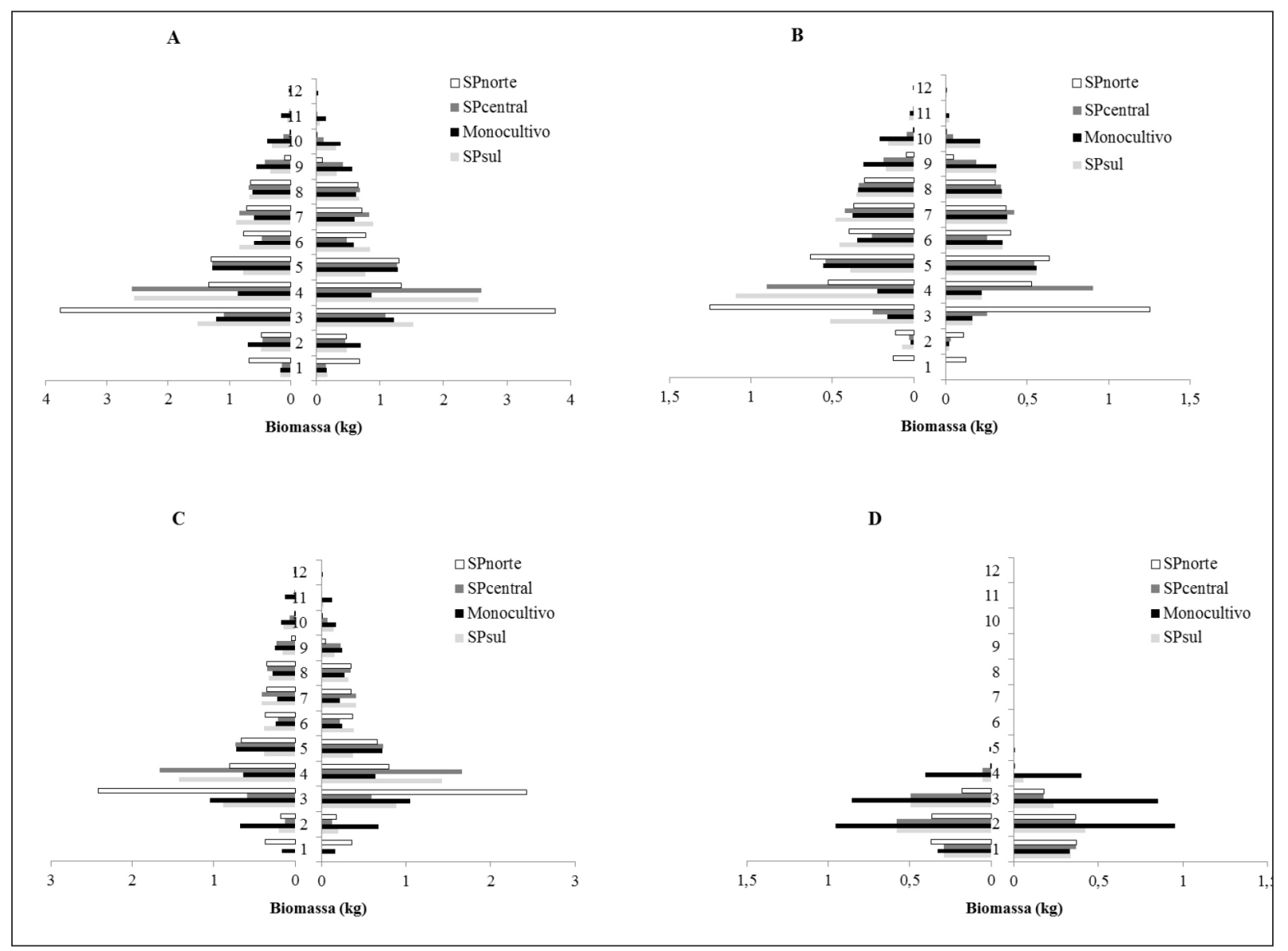

A maior biomassa total produzida por árvores em $\mathrm{SP}_{\text {norte, }}$ quando comparadas a $\mathrm{F}$, e a maior conicidade e produção de biomassa de folhas e galhos vivos nas partes mais baixas da copa quando comparada a $\mathrm{SP}_{\text {central }}$ e $\mathrm{SP}_{\text {sul }}$ pode ser explicada pela orientação das faixas de plantio (posicionadas em leste - oeste) e pela posição aparente do sol ao longo do ano na latitude em que foi realizado o experimento.

De acordo com Martins, Shimizu e Ferreira (2000), árvores que recebem grande quantidade de luz em toda a extensão vertical da copa desenvolvem ramos mais vigorosos desde a parte mais baixa do fuste. Devido à maior quantidade de ramos vigorosos, as árvores desenvolvem maior diâmetro do tronco na sua porção inferior com rápido afilamento em direção ao ápice, resultando em toras de maior conicidade. 
Ao meio-dia, o ângulo zenital máximo ao norte das faixas de plantio de eucalipto chega a aproximadamente $35,31^{\circ}$ no dia $21 / 06$ (solstício de inverno no hemisfério sul), enquanto que o ângulo zenital máximo ao sul das faixas de eucalipto atinge apenas $11,56^{\circ}$, aproximadamente, no dia $20 / 12$ (solstício de verão no hemisfério sul). Ou seja, os raios solares nesta latitude, além de incidirem por mais tempo nas árvores com face de exposição norte, também atingem uma maior intensidade por unidade de área devido à maior perpendicularidade. Soma-se isso o fato de que na estação chuvosa, a nebulosidade é muito alta, reduzindo ainda mais a intensidade da radiação solar incidente na face sul.

\section{Conclusões}

O sistema de plantio não teve influência sobre a biomassa individual alocada no tronco, porém, na comparação com o monocultivo, as árvores plantadas em sistema silvipastoril apresentaram maior biomassa alocada na copa, menor altura total e maior conicidade do tronco.

Não houve efeito da exposição solar sobre a produção total de biomassa nas árvores plantadas em sistema silvipastoril, entretanto, árvores com face de exposição norte foram mais baixas e cônicas e produziram mais galhos e folhas nas partes inferiores da copa.

\section{Agradecimentos}

Os autores agradecem ao Conselho Nacional de Desenvolvimento Científico e Tecnológico (CNPq) pelo apoio financeiro.

\section{Referências}

ALVES, A. M. C. Quantificação da produção de biomassa e do teor de carbono fixado por clones de eucalipto, no Pólo Gesseiro do Araripe-PE. 2007. 62 f. Dissertação (Mestrado) - Universidade Federal de Pernambuco, Recife, 2007.

ALZATE, S. M. B.; TOMAZELO FILHO, M.; PIEDADE, S. M. E. Variação longitudinal da densidade básica da madeira de clones de Eucalyptus grandis Hill ex Maiden, E.saligna Sm e E.grandis x urophylla. Scientia Forestalis, Piracicaba, n. 68, p. 87-95, 2005.

BERNARDO,A. L. et al. Effect of spacing on growth and biomass distribution in Eucalyptus camaldulensis, E. pellita, and E. urophylla plantations in southeastern Brazil. Forest Ecology and Management, Amsterdam, v. 104, p. 1-13, may 1998.

BRAGA, F. A. et al. Características ambientais determinantes da capacidade produtiva de sitios cultivados com eucalipto. Revista Brasileira de Ciência do Solo, Viçosa, MG, v. 23, p. 291-298, 1999.

CARVALHO, A. M.; NAHUZ, M. A. R. Valorização da madeira do híbrido Eucalyptus grandis x urophylla através da produção conjunta de madeira serrada em pequenas dimensões de madeira, celulose e lenha. Scientia Forestalis, Piracicaba, n. 59, p. 61-76, 2001.

CEZANA, D. P. et al. Efeitos de diferentes classes de altura e intensidades de desrama artificial sobre o crescimento de um híbrido de eucalipto. Floresta, Curitiba, v. 42, n. 1, p. 137-144, 2012.

FERREIRA, D. H. A. A. et al. Crescimento de clones de Eucalyptus urophylla x E.grandis em diferentes espaçamentos. Floresta, Curitiba, v. 44, n. 3, p. 431-440, 2014.

GONÇALVES, D. R. C. Avaliação do efeito da exposição solar sobre o crescimento de plantios comerciais de Eucalyptus sp. na região sudoeste do estado de São Paulo. 2015. $90 \mathrm{f}$. Dissertação (Mestrado em Ciências Florestais) - Escola Superior de Agricultura "Luiz de Queiróz", Universidade de São Paulo, Piracicaba, 2015. 
INTEGRAÇÃO lavoura, pecuária, floresta: tecnologia social que gera trabalho e renda, produz mais alimentos e preserva o meio ambiente. Brasília: Fundação Banco do Brasil; Fundação Casa do Cerrado, [2013]. Disponível em: http://www.fbb.org.br/reporter-social/midiateca/cartilha-ilpf.htm. Acesso em: 15 abr. 2015.

KOZLOWSKI, T. T.; KRAMER, P. J.; PALLARDY, S. G. The physiological ecology of woody plants. San Diego: Academic Press, 1991. 657 p.

LELES, P. S. S. et al. Crescimento, produção e alocação de matéria seca de Eucalyptus camaldulensis e Eucalyptus pellita sob diferentes espaçamentos na região de cerrado, MG. Scientia Forestalis, Piracicaba, n. 59, p. 77-87, 2001.

MACEDO, R. L. G. et al. Eucalipto em sistemas agroflorestais. Lavras: Editora da UFLA, 2018. 352 p.

MARTINS, E. G.; SHIMIZU, J. Y.; FERREIRA, C. A. Desempenho de procedências de grevílea em Quedas do Iguaçu, PR. Boletim de Pesquisa Florestal, Colombo, n. 40, p. 45-56, 2000.

NEVES, T. A. et al. Qualidade da madeira de clones de Eucalyptus em diferentes idades para a produção de bioenergia. Revista de Ciências Agrárias, Recife, v. 56, n. 2, p. 139-148, 2013.

OLIVEIRA, C. H. R. et al. Área foliar e biomassa de plantas intactas e de brotações de plantas jovens de clone de eucalipto em sistemas agrossilvipastoris. Revista Árvore, Viçosa, MG, v. 32, n. 1, p. 59-68, 2008.

OLIVEIRA, T. K. et al. Desempenho silvicultural e produtivo de eucalipto sob diferentes arranjos espaciais em sistema agrossilvipastoril. Pesquisa Florestal Brasileira, Colombo, n. 60, p. 1-9, 2009.

OLIVEIRA NETO, S. N. et al. Produção e distribuição da biomassa em Eucalyptus camaldulensis Dehn. em resposta à adubação e ao espaçamento. Revista Árvore, Viçosa, MG, v. 27, n. 1, p. 15-23, 2003.

PATIÑO-VALERA, F.; KAGEYAMA, P. Y. Interação genótipo x espaçamento em progêneies de Eucalyptus saligna Smith. IPEF, Piracicaba, n. 39, p. 5-16, 1988.

PEREIRA, A. R.; ANGELOCCI, L. R.; SENTELHAS, P. C. Agrometeorologia: fundamentos e aplicações práticas. Guaíba: Agropecuária, 2002. 478 p.

PEZZOPANE, J. E. M. Caracterização microclimática, ecofisiológica e fitossociológica em uma floresta estacional semidecidual secundária, em Viçosa, MG. 2001. 240 f. Tese (Doutorado em Ciências Florestais) - Universidade Federal de Viçosa, Viçosa, MG, 2001.

PROTASIO, T. P. et al. Clones comerciais de Eucalyptus de diferentes idades para o uso bioenergético da madeira. Scientia Forestalis, Piracicaba, v. 42, n. 101, p. 113-127, 2014.

REINER, D. A.; SILVEIRA, E. R.; SZABO, M. S. O uso do eucalipto em diferentes espaçamentos como alternativa de renda e suprimento da pequena propriedade na região do sudeste do Paraná. Synergismus Scyentífica, Pato Branco, n. 6, v. 1, 2011.

RIGHI, C. A. et al. Effect of shade on biomass accumulation and partitioning for Eucalyptus camaldulensis sprouts. Journal of Sustainable Forestry, [S.1.], v. 35, n. 1, p. 75-87, 2016.

SANTANA, R. C. et al. Estimativa de biomassa de plantios de eucaliptos no Brasil. Revista Árvore, Viçosa, MG, v. 32, n. 4, p. 697-706, 2008.

SANTOS, S. R.; SANSÍGOLO, C. A. Influência da densidade básica da madeira de clones de Eucalyptus grandis $x$ Eucalyptus urophylla na qualidade da polpa branqueada. Ciência Florestal, Santa Maria, v. 17, n. 1, p. 53-63, 2007.

SANTOS, L. C. et al. Propriedades da madeira e estimativas de massa, carbono e energia de clones de Eucalyptus plantados em diferentes locais. Revista Árvore, Viçosa, MG, v. 36, n. 5, p. 971-980, 2012 . 
SCHNEIDER, P. R.; SCHNEIDER, P. S. P. S. Introdução ao manejo florestal. Santa Maria: FACOS; UFSM, 2008. $566 \mathrm{p}$.

SCHUMACHER, M. V.; CALDEIRA, M. V. W. Estimativa de biomassa e conteúdo de nutrientes de um povoamento de Eucalyptus globulus (Labillardière) Sub-espécie maidenii. Ciência Florestal, Santa Maria, v. 11, n. 1, p. 45-53, 2001.

SOUZA, A. P. et al. Classificação climática e balanço hídrico climatológico no estado de Mato Grosso. Nativa, Cuiabá, v. 1, n. 1, p. 34-43, 2013.

TONINI, H. et al. Biomassa e área foliar de clones de Eucalipto em ILPF: implicações para a desrama. Nativa, Sinop, v. 4, n. 5, p. 271-276, 2016.

WEST, P. W. Growing plantation forests. Berlin: Springer, 2006. 304 p. 